\title{
Story-making as methodology: Disrupting dominant stories through multimedia storytelling
}

Carla Rice

University of Guelph

Ingrid Mündel

University of Guelph

This is the peer reviewed version of the following article: Rice, C., \& Mündel, I. (2018). Storymaking as methodology: Disrupting dominant stories through multimedia storytelling. Canadian Review of Sociology, 55(2): 211-231, which has been published in final form at https://doi.org/10.1111/cars.12190. This article may be used for non-commercial purposes in accordance with Wiley Terms and Conditions for Use of Self-Archived Versions.

\section{Recommended citation:}

Rice, C., \& Mündel, I. (2018). Storymaking as methodology: Disrupting dominant stories through multimedia storytelling. Canadian Review of Sociology, 55(2): 211-231.

https://doi.org/10.1111/cars.12190 


\title{
Story-Making as Methodology: Disrupting Dominant Stories through Multimedia
} Storytelling

\author{
Carla Rice and Ingrid Mündel \\ University of Guelph
}

\section{Abstract}

In this essay, we discuss multimedia story-making methodologies developed through Re•Vision: The Centre for Art and Social Justice that investigates the power of the arts, especially story, to positively influence decision makers in diverse sectors. Our storymaking methodology brings together majority and minoritized creators to represent previously unattended experiences (e.g., around mind-body differences, queer sexuality, urban Indigenous identity, and Inuit cultural voice) with an aim to building understanding and shifting policies/practices that create barriers to social inclusion and justice. We analyze our ongoing efforts to rework our storytelling methodology, spotlighting acts of revising carried out by facilitators and researchers as they/we redefine methodological terms for each storytelling context, by researcher-storytellers as they/we rework material from our lives, and by receivers of the stories as we revise our assumptions about particular embodied histories and how they are defined within dominant cultural narratives and institutional structures. This methodology, we argue, contributes to the existing qualitative lexicon by providing innovative new approaches not only for chronicling marginalized/misrepresented experiences and critically researching selves, but also for scaffolding intersectional alliances and for imagining more just futures. 
Go to www.projectrevision.ca/story-making. Type in the password "disrupting" to access the album "Story-Making as Methodology: Disrupting Dominant Stories through Multimedia Storytelling." Please note: the videos are intended for readers only and are not for public screening.

In this paper, we reflect on the evolving multimedia storytelling method developed by the Re・Vision Centre for Art and Social Justice that investigates the power of the arts, and especially of story, to positively influence decision makers and practitioners in diverse sectors. We sketch out Re•Vision's approach and the process that we have developed to help people craft preferred stories, a method that brings professional into play with community arts. Drawing on the Centre's collaborative work with Urban Indigenous, Inuit, Queer, nonbinary, trans, and disability-identified artists and communities, we consider the power of story-making methods to (re)author identities and selves, and the potential of well-crafted and well-curated stories to create systemic change. We focus here specifically on ongoing efforts to rework and revise our storytelling methodology - acts of revising carried out by facilitators and researchers as they/we redefine methodological terms for each storytelling context, by researcherstorytellers as they/we rework material from our lives, and by receivers of the stories as we revise our assumptions about particular bodies and histories and how they are defined within dominant cultural narratives and institutional structures. We follow feminist poet Adrienne Rich when she states, "revision—the act of looking back, of seeing with fresh eyes, of entering an old text from a new critical direction-is for women more than a chapter in cultural history: it is an act of survival" (Rich 1972:18). Rich's framing of revision as survival helps underscore the urgency of story-making and listening, drawing us in as experts on our own lives and asking us to take responsibility for the stories we share and hear. Rich acts as a mentor and guide in our "revising" work not only as a poet and writer, but also in the role she played as an educator; in the late 1960s, Rich distanced herself from her role in upholding what she came to see as an elitist literary culture to commit to the "poetics of the everyday." We punctuate this theme of revising — of our methods, subjectivities, and interrelationalities-with stories made in $\mathrm{Re} \cdot V i s i o n$ workshops, which give readers a sampling of the diverse work 
created through our methodology. We conclude by reflecting on how the stories produced through this methodology may be pedagogical and impactful, not in teaching people the correct or right way to think, feel, or act but rather in expanding possibilities for living in/with difference. We make the case that storytelling methodologies contribute to our expanding qualitative research lexicon in the social sciences by offering novel approaches not only for chronicling marginalized voices, but for scaffolding intersectional and intersectorial alliances (across institutions and communities) for intervening in systemic inequities and imagining more just futures.

\section{FROM DIGITAL TO MULTIMEDIA STORY-MAKING}

In the section that follows, we introduce the explicitly activist-oriented, art-based research projects undertaken by $\mathrm{Re} \cdot V i s i o n$ in collaboration with diverse social justiceseeking groups on the lands currently known as Canada. We situate our methodology as it has evolved in relation to local and global activist arts movements as well as critical arts-based research methodologies, particularly visually-oriented, story-based methods. Drawing on these traditions, we begin to build a case for story as both methodology and method: for how we might theorize multimedia story-making as knowledge producing as well as understand it as a critical and processual praxis for generating multiperspectival knowledges about self, other, and world. By situating Re•Vision's work within these movements and methodologies, we acknowledge the lineages that inform our method and that continue to nourish our vision: a world in which complexity and difference are welcomed. At the same time, we gesture toward some of methodological innovations developed by $\mathrm{Re} \cdot \mathrm{V}$ ision that push this project forward.

The Re•Vision Centre is home to a number of research projects dedicated to exploring ways that a range of communities can use arts-informed research to advance social inclusion, well-being, and justice. Broadly, we look at the power of the arts to open up conversations about difficult or sensitive topics in health care, education, business, and the arts/culture sectors. We accomplish this work through REDLAB, which is a physical space and a mobile media laboratory for producing and editing digital media at the University of Guelph. In Re•Vision's first six years, we have run close to 100 storytelling workshops across Canada for diverse projects involving people 
with disabilities and health-care providers on changing conceptions of disability in health care (Rice, Chandler, and Changfoot 2016; Rice and Mündel forthcoming; Rice et al. $2015,2016,2017)$; racialized and nonracialized youth with mental health issues, police, and mental health workers on system responses to youth with mental health issues (Ferrari, Rice, and McKenzie 2015); Indigenous and non-Indigenous students, teachers, and parents on what is needed to decolonize public schools (Rice et al. 2018a); with academics on the values underpinning, and their relationship to, their research programs (Rice et al. 2018b); with Inuit professional artists and youth on building Inuit cultural voice; with aging activists on disability and aging arts movements; with queer women on speaking back to obesity epidemic and eating disorder discourses that erase or problematize queer bodies (Lind et al. 2017; Rice et al. forthcoming; Rinaldi et al. 2016); with trans, genderqueer, and nonbinary people on mental health-care experiences; and finally with autistic people, family members, and allies on enacting critical disability studies in education.

$\mathrm{Re} \cdot V i s i o n$ situates its work within activist arts traditions in the twentieth century as well as the principles/practices of critical arts-based research. Activist art has had many traditions around the world and over time. During the early twentieth century it included the political work of artists opposing fascism prior to World War II (Platt 1997) and over the latter half of the twentieth century, of feminist, queer, and decolonizing artists addressing political problems such as imperialism, homophobia, and racism and sexism (Felshin 1995). Today activist artists in the west and globally engage with an immensely wide range of sociopolitical issues and contribute their creative labor to intervene in the destructive structures and relations of colonialism and racism (Ortega 2014); disablism and ableism (Raphael 2013); and neoliberal capitalism (Dufour 2002). Activist art can take many forms: social justice movements such as Idle No More and Occupy have used performance and other art techniques in direct actions such as street protests; and practices of protest (songs, chants, drumming, etc.) in themselves have been considered artistic. In the online feminist, antiracist, decolonizing, environmental, and disability justice movements, visual messaging plays an extremely significant role in pushing against dominant representations and taken-for-granted understandings that 
serve hegemonic interests (Cronin 2011). Researcher Abeyami Ortega (2014) neatly describes activist art as "artivism" (p. 86).

In addition to activist art, our multimedia storytelling is guided by the principles and practices of critical arts-based research, specifically storytelling methods that incorporate multimedia elements (music, still and moving images, and ambient sound). Following many leading methodologists, we use the terms "arts-based" and "artsinformed" research interchangeably (Leavy 2009) to signal "methodologies that follow from a constructivist, emotive, empiricist research aesthetic" (Finley 2008:79). In last 20 years, arts-based methods have emerged as a "challenge to logical positivism and technical rationality as the only acceptable guides to explaining human behaviour and understanding" as well as an intervention into the dichotomy of the academy and community that recognizes the knowledge making of everyday people by cocreating knowledge that is "accessible, evocative, embodied, empathic, and provocative" (Knowles and Cole 2008:33). Congruent with the goals of activist art-teaching counterhegemonic perspectives and inciting debate-Re•Vision's arts-based research approaches stress criticality. We define critical arts-based research as a postmodern, participatory, political, and process-oriented approach to research, which Finley, Vonk, and Finley (2014) describe as "the dialogical performance of critical theory using artmaking as method" (p. 622) and Dwight Conquergood (2002), as a subjugated method "grounded in active, intimate, hands-on participation and personal connection," which offers a dense multi-sensory "view from a body" (p. 146).

At the heart of Re・Vision's uptake of these methodologies is the "coming together" of storytelling and social change - the creating and sharing of new understandings of difference that disrupt dominant narratives and open possibilities. We take a multimedia narrative approach adapted from digital storytelling, a method developed in the mid-1990s by the StoryCenter in Berkeley, California as a digital reworking of the live theater and radio genres of autobiographical monologue (Benmayor 2008; Lambert 2013). Although terms such as digital storytelling, ethnocinema, and participatory filmmaking have emerged in the last 30 years for referring to community-based filmmaking across the social sciences, we use the phrase "multimedia story-making" as "multimedia" encompasses the diverse media forms and 
genres from which we draw (such as creative writing and performance) and "story" places emphasis on the constructivist, storied nature of all knowledge claims. For us, multimedia also distinguishes our method from that of other digital storytelling projects in how we invite professional artists and community members to work together in their creation of stories, in this way emphasizing artful retellings and experimentation over straightforward narrative. However, we also recognize that theoretically and epistemologically, the work of centering marginalized perspectives comes from a much longer lineage connected to popular education practices, decolonizing movements, qualitative research traditions, and feminist historiography among others. From the outset, people have found the digital storytelling method particularly germane to social change efforts. The act of making space for people to tell their own stories coupled with the translation of these stories into a widely shareable multimedia format has allowed renewed and varied engagements with systemic issues of racism, sexism, ableism, and colonialism.

For example, Indigenous communities have used digital storytelling to disrupt stereotypes of First Nations, Inuit, and Metis people (Willox, Harper, and Edge 2012); to decolonize research methods and shift what counts as knowledge by speaking back to colonial legacies and logics; to give expression to and witness the telling of colonial traumas (Beltrán and Begun 2014); and to give Indigenous youth opportunities to create new understandings of the present and new possibilities for futures. Similar findings echo throughout storytelling projects involving other marginalized groups including undocumented migrants in Ireland (Alexandra 2008); teenage mothers (Gubrium, Krause, and Jernigan 2014); and trans-individuals (Vivienne 2011). Education scholar Chloe Brushwood Rose (2009) argues that the "story" part of digital storytelling holds particular promise as narrative is an intermediate area of experience. Stories convey both what we do and do not know about ourselves, creating a productive tension between our self-expression (meanings we convey) and our self-knowledge (our current knowledge of ourselves). This tension allows us to make discoveries about ourselves in the process of creating and viewing our stories, especially if we recognize that narratives are storied rather than unmediated reflections of experience (Brushwood Rose 2009). 
Building on and apart from Brushwood Rose's psychoanalytic analysis of selfnarratives, we approach storywork from a feminist posthumanist processual perspective (Braidotti 2013; Rice et al. 2016). This view understands story-making as potent not (only or primarily) for unearthing that which we did not previously know about ourselves (the orientation of psychoanalysis and psychology generally), but for bringing into being that which we might be coming to express and understand about our subjectivities and social identities through our ongoing encounters with the world. The former approach might be thought of as resting on past-oriented humanist theories of the self insofar as it understands human subjectivity as organized according to universal structures (whether of id, ego, super-ego, or other more contemporary variations); and the latter might be understand as resting on posthumanist future-oriented theory in how it rethinks subjectivity in nonuniversalist terms as continuously changing and revising in relation to the becoming of the world. In other words, while the former focuses on knowledge about the self that is hidden, repressed, or held outside of conscious life, the latter emphasizes knowledge and learning generated in/of conscious life through the confrontations that occur continuously between self and world.

Drawing on activist arts and processual theoretical perspectives, Re $\bullet$ Vision adopts and adapts these methodologies and methods by creating workshops where people unpack and "talk back to" received representations and make new meanings through making multimedia stories-one- to five-minute-long videos that pair personal/community narratives with visuals such as video, artwork, photos, and more. Our workshops are designed for 12 to 15 participants and typically take place over the course of two to five days. They involve an in-depth framing of the themes or issues that bring storytellers together; a story circle where participants share initial ideas around the experience or moment they would like to develop; writing exercises to help participants develop their scripts; tutorials on using audio, video, and editing software and equipment; and full technical, writing, and conceptual support for the workshop's duration to help participants from script development to finished video. Participants are recruited through networks relevant to each project and occupy diverse locations relative to the issues under investigation (institutions, communities, etc.). They may or may not be practicing artists but must identify (wholly or partially) as members of, or 
allied with, the specific aggrieved groups being centered. To conclude each workshop, participants are invited to share their stories in a final screening and everyone leaves the workshop with their own video. To date, we have generated close to 500 stories, which have been screened widely and disseminated across diverse academic and nonacademic channels. During this period, we have also conducted extensive research on the impacts of story-making and sharing on both makers and audiences. 1

In our discussion here, we focus specifically on the ongoing acts of revising practiced in our framing of methodology and in the multimedia story-making process itself. In this way, we follow from Rich's centering of the poetics of the everyday and on pedagogical and communication researcher Alexandra Georgakopoulous' development of small stories research to return attention not just to storytelling, but to emerging or partial stories and story-revising as a critical process for opening up conversations about injustice and new possibilities for being and becoming. Georgakopoulou (2015) writes, "the spirit of small stories research is all about recognizing the pluralism, heterogeneity, and productive coexistence of narrative activities, big and small, in the same event, by the same teller, and so on" (p. 256). Georgakopoulous' (2015) contestation of story "as a single event unfolding in a linear sequence, a neatly delineated activity with a clear beginning, middle, and end" is particularly germane to our understanding and use of storytelling as "messy" and "developing without easily identifiable endpoints and in different environments and media" (p. 258). Although participants engage in a process of "telling" the self through our story-making workshops, there is no expectation that the self that is being told is presented as coherent and unfragmented, or that the stories should follow a clear narrative arch.

\footnotetext{
${ }^{1}$ Our stories have traveled. Stories from the decolonizing collection have been featured in an art exhibition at the Ontario Legislature where senior Ministry of Education and Ministry of Aboriginal Affairs policy makers and politicians viewed the stories alongside the works of contemporary Indigenous artists; and they have been screened for Directors of Education and Trustees from School Boards across Ontario as well as for senior staff at the Toronto District School Board. Those in the re-storying disability collection have been screened with senior medical and administrative staff and board members of major teaching hospitals in southern Ontario, as well as in health-care professional education programs throughout Ontario including medical schools, as well as nursing, social work, psychology, and occupational therapy programs. The stories also caught the attention of the Ontario Arts Council and Tangled Art + Disability, Ontario's leading disability arts organization, which lead to a screening at the Toronto International Film Festival and the hiring of one researcher on our project, Dr. Eliza Chandler to conduct a research study that informed the establishment of a disability arts funding stream at the Ontario Arts Council.
} 
Rather, our storywork engages in telling moments and in exploring the messy, fragmented nature of identities and subjectivities as these are storied and restoried in the social relations that unfold in, around, and beyond our workshops.

\section{STORY-MAKING AS REVISION: REVISING METHODOLOGIES,}

\section{SUBJECTIVITIES, RELATIONALITIES}

\section{Revising Methodologies}

We understand multimedia storytelling approaches as methods for working and reworking the material of our lives -including our subjectivities and relationalities_and for communicating these provisional knowledges to others. However, since the process of conducting socially engaged research inevitably involves modifying our procedures to suit diverse and changing contexts (including different research goals, participants, and social fields, our changing philosophical stances, etc.), we further understand these methods as processual-as in a continual process of construction and revision. For just as we (as researchers and people) understand selves, others, social worlds, and our storying of these as ever in flux, so too do we recognize that our methods are always shifting and moving, changing in response to different situations, as well as the specific configuration of subjectivities, social issues, technologies/tools, and energies brought into the research space. Put differently, we do not see story-making as we undertake it as a prescriptive method (with step-by-step procedures) that is rooted in a scientific and realist paradigm but a processual posthumanist one that emphasizes the qualities, relationalities, and potentialities of the specific localities, subjectivities, and technologies that present themselves in the moment. As visual and sensory ethnographer, Sarah Pink (2015) notes, "methods themselves have biographies, they evolve through different projects ..." (p. 11). While Pink orients to the histories of visual and sensory methods, we are interested in what happens when they are taken up-how they stretch, move, and transform with each research project. Similarly, socio-narratologist Arthur Frank (2010), speaking about the challenges of overly prescriptive narrative "methods" (language he gently contests) argues, "stories are too lively and too wild to be tied up" (p. 1). Approaching method as open-ended and malleable means that we need to 
anticipate, prepare for (to the extent possible), and welcome the disruption and transformation that occurs within the unfolding of each inquiry. We view this as a learning process and as a fundamental part of the search for understanding and meaning - rather than seeing discovery as that which emerges from research "findings" alone. Though at its heart, our method - with its emphasis on story and social justicehas remained intact, our methodology has moved substantively and continues to change in surprising ways along with the context, community, and issue(s) under investigation. With this movement, certain core ethical principles stay the same: we take on projects that address pressing social problems; we approach these using a social justice lens; we recognize that all accounts, whether written, told, or imag(in)ed, are partial truths and that the truths of aggrieved groups must be proliferated if we hope to create a more just society; and we work in highly collaborative, community-driven ways that bring members of aggrieved and advantaged groups together to restory experiences and perspectives. We hold to these principles to connect people's material realities with the discursive regimes in which they are immersed in a way that makes visible and indeed centers the creativity and agency of members of justice seeking groups.

\section{Genealogies of stories and storytelling in research}

The history of storytelling is as old as the history of human social life itself, and in this sense, we might think about storytelling as the original qualitative research method. In the western cannon, major thinkers have understood story as a technique for making sense of self, other, and world, as a device for communication, and hence, as a social practice that can be explored and theorized. If we traced the recent history of theorizing about story in our own sociohistorical contexts as white settlers situated in both critical western and Indigenous decolonial traditions, we might organize its genealogy into two interrelated strands: the first, we would call story in theory, and the second, story as theory. Story in theory-or theories about what is, and is not, a story and about the work that stories do in the world-emerged from developments in the fields of literary and media studies over the twentieth century, and especially narrative theories and methodologies arising from structuralist and poststructuralist thought (Bal 1997; Fludernik 2005). With the proliferation of stories across diverse media-including fiction 
and nonfiction, conversations, narrative representations in medical and legal contexts, news stories, theater, video, social media, and much more--a wide spectrum of disciplines and professions have embraced narrative concepts and methodologies, using these to examine the narrative strategies employed by diverse storytellers in many different contexts.

Riding this narrative wave, researchers from different disciplinary traditions have developed methodologies that mobilize narrative theory in order to capture and analyze people's stories of their lives. Narrative methods and techniques of analyses are now firmly established in the research lexicon in history (Cole and Knowles 2001), anthropology (Behar 1996), psychology (White 2007), sociology (Kim 2015; Reissman 2008), and beyond. The professions and those who study them also have adopted the concept of narrative, especially those working in health care (Frank 2010), education (Clandinin and Connelly 2000), and organizational management (Boje 2011). Particularly salient to the umbrella of narrative methodologies is the idea that storytelling is a subjective, situated, and collaborative practice that involves storytellers and audiences interacting in specific settings; this makes the historical, cultural, and social contexts of storytelling essential to interpretation in story-based research, whether the stories are visually based or not. Researchers, however, vary considerably in how they make meaning of and mobilize the concept of narrative in their inquiries, analyzing narratives found everywhere and eliciting multiple kinds of stories: life histories, stories of specific experiences, conversational stories (that evolve through dialogue), and highly reflexive autoethnographies. In all of these cases, what distinguishes "story" from other forms of discourse is the teller's selection, organization, and representation of happenings from the continuous flow of life experiences.

Much of the story-based research emerging from the western cannon has taken up story in theory - as a mode of organizing and sharing experience that can be theorized. From Indigenous perspective, however, story itself is theory. As theory, stories encode people's worldviews and convey their deepest beliefs about the world. This is what Cherokee writer Thomas King (2003) means when he writes, "The truth about stories is that that's all we are" (p. 3). Following Indigenous traditions, many Indigenous scholars, including Jo-ann Archibald (Stó:lo), Lenore Keeshig Tobias 
(Anishinaabe), and Paula Gunn Allen (Laguna, Sioux), view stories as carriers of people's knowledge and values - as speech acts that have the power to make and change the world. For Archibald (2008:3), the term "storywork" captures the centrality of story as Indigenous methodology because it signifies "that our stories and storytelling [are] to be taken seriously," and points to the work that stories do in translating/making meaning of the world. Building on this understanding, King (2003) reminds us: "Stories are wondrous things. And they are dangerous" (p. 9). Nigerian novelist Chimamanda Adichie (2009) also tells of the danger of the "single story," the repeatedly told story that becomes the only way an individual or group is identified. From these traditions, we learn that stories are the things that bring us together and teach us about the world; yet they are also the things that break us apart and make us invest in ways of being that are destructive to each other and to the world. At Re•Vision, we investigate two intriguing and pressing questions related to this problematic: how we move past the dominant narrative without producing a single counter story that similarly ensnares us; and how we listen to each other and reflect deeply on the implications of the stories we tell. We continue to live and work in ongoing dialogue with this problematic, by committing to the continual act of revising received narratives and remaining nimble and improvisatory in the way our storywork unfolds. Part of the importance of this work is how this kind of storytelling, the telling of multiple, interconnected "small" and "big" stories is that it "make[s] visible the teller's inconsistencies, the troubled identities, the ambivalent relationships with big issues such as race, gender, ethnicity, etc." (Georgakopoulou 2015:264). These points of disjuncture and fissures offer openings for new and collective reckonings that interrogate and potentially rewrite existing social scripts. Genealogies of images and image making in research

In the history of image-based methods, approaches to image in research follow a similar trajectory to that of story: researchers have investigated image in theory and image as theory. The use of images in research dates back to the invention of the camera in the nineteenth century; later, the cultural turn in 1980s combined with the ubiquity of images in people's lives opened the door for film and still image to become more acceptable forms of representation in research. As visual technologies have become cheaper, more widely available, and extensions of embodiment for many, more 
researchers are interested in visual research methods and visual research itself has become increasingly accessible. Early visual sociologists such as Gillian Rose (2016) posited that the visual should be engaged with not simply as a mode of recording data or illustrating text, but as a medium through which new knowledge and critiques might be created. More recently, Pink (2015) has argued that images are part of our contemporary reality, so attending to them "not only creates possibilities in terms of methods we can use but in terms of the way we understand the visual and vision theoretically" (p. 31). For Pink and others, the shift from text-based to image-based theory invites us to interrogate what is possible to learn from images and how these media might shape our thinking. From our vantage as scholars who identity as and/or conduct research with people living with disabilities in a culture where image is hegemonic, we are particularly interested in how we might translate learnings taken from visual field into other sensory media in order to make them accessible to what the self-described Vancouver-based, nonvisual (legally blind) artist Carmen Papalia (2018) calls "non-visual learning" (para 2).

\section{Story-making as revision}

By bringing together analyses of the visual and the material dimensions of our work, and by acknowledging the discursive constitution of our stories, we also push against the "seeing is believing" paradigm. At the same time, we actively make space for the material, expressive, embodied experiences of coresearcher/participants as in ongoing dialogue with broader forces that work to dehumanize, undermine, fix, and define nonnormative voices, stories, and bodies, as evidence, as proclamations that our current coordinates of existence are untenable. Frank (2010) comments on the danger of equating stories with evidence when he writes "social scientists and various researchers using social scientific methods have been too exclusively concerned with stories as self-reports that provide more or less valid information about people's lives, and have neglected storytelling as a pervasive and crucially important human activity" (p. 18). The point, then, is not newness, new facts, original ideas; the point is to recognize stories as makers and shapers of the social and the kinds of social life that we imagine, who is included, whose lives are valued. As such, when we speak about story-making, we are speaking both about the collective process involved in "making" 
stories that draw on all kinds of received narrative resources, visual terrains, images, and art practices and to the process of making and remaking the social worlds that we inhabit, the selves that we imagine and live. We make stories at the same time that stories make us.

Edges

Arts-based community maker Elizabeth Jackson powerfully theorizes how stories move and work and make us. In her video, Edges, stories are figured as shape-shifters, "layers build up, until the story does not remember how it began." (To view go to www.projectrevision.ca/story-making and type in the password "disrupting.") The video begins at the edges - at points of intersection, where borders and boundaries begin and end: "The thing about edges is, they blur. There are places where skin meets air. Spaces within solids." These boundaries are material: the physical boundaries of bodies, touching, of a schoolyard fence; and they are also discursive: the story of a man as it layers and unfolds in a quiet encounter with a small child, and in news accounts that later tell of a terrifying abduction carried out by the same man. In this way, the blurring emerges both as beautiful, in moments of reaching, relational connection-and horrifying -in the violence of a schoolyard fenced boundary being transgressed, "Moving through borders, boundaries, imagined, tangible, permeable, all." Jackson resists the pull for narrative closure or for a final authoritative read on two seemingly irreconcilable encounters with the same man: one encounter where her daughter sees a man on a bench who has clear, gentle eyes and a kind face and chooses to give him her birthday money and a second encounter where the same man abducts a small child from the school yard where Jackson's daughter is playing. Instead stories show up in Jackson's piece as volatile, living, generative, open; stories are alive. Frank (2010) speaks to the materiality and liveness of stories when he writes "letting stories breathe is a claim that stories are as much physical as metaphysical. As stories tell people who they are, those people are embodied as much by stories as by their flesh" (p. 146). Illustrating this, Jackson's narrative reflects on the fleshiness of stories and the porousness of bodies-where stories end and subjectivity begins are blurred as the narrative doubles back, revises, and unravels. By highlighting the wonder/danger of 
stories and their making, Jackson's video points to the necessity of acknowledging and taking responsibility for our part in moving with and through stories.

Jo-ann Archibald similarly suggests that stories make us when she describes an experience of telling a story, "The Bird in the Tree" and how the story took on a life of its own in the responses from the students listening. She uses it as an example of a story taking on a "life" and becoming a teacher (Archibald 2008:95). Importantly, the way Archibald speaks about storywork focuses on the collective process and the kind of life stories have when told and held in a circle with others. For her, the use of a speaking stone or rock, food, and sitting together are integral parts of what keeps "the story going and useful to people" (Archibald 2008:97). The circle, rock, and food become defining boundaries and signals that open up space for a story to make.

\section{The storyteller}

The second video we feature punctuates the theme of story-based methods as theoretical and processual by exploring how factual accounts, like other knowledge claims, are partial and situated accountings of the world, both shaped by and shaping the perspectives of the observer. In The Storyteller, white-settler journalist, Laura Eggertson, opens by pairing visual headlines of one of her news stories "Nunavut youth saturated in the realities of suicide" with the haunting voices of Inuit youth, with those whose deeply personal stories of suicide carry the echoes of a grim history of whitesettler colonial violence. (To view, go to www.projectrevision.ca/story-making and type in the password "disrupting.") In bearing witness to Inuit stories of colonial trauma, she poses thorny ethical questions about the relationship between stories (and the knowledge they carry) and power: How can she, as a white-settler journalist, do justice to Inuit experiences? How can any observer, borrowing from essayist Susan Sontag (2003), ethically recount the pain of others? In these tellings, whose perspective becomes the official story? Pressing herself further still, she raises difficult ethical dilemmas about her public and private positionalities: How and to what extent has she adopted the role as storyteller as a comfortable mantle in order to avoid telling her story? And, how can she trust others to tell her own deeply painful stories of trauma and betrayal? As Eggertson recounts the difficulty of sharing these stories an audio track of a song plays that repeats the phrase "have a little faith in me," underscoring the 
simultaneous intellectual, ethical, and relational work required in telling trauma stories on behalf of a person or community, especially when one has resonant experiences and is a member of the group implicated in creating the conditions for that trauma.

\section{Revising Subjectivities and Identities}

How does this kind of thinking about story-making impact our roles as researchers and facilitators? We have both been committed to storywork for a long time-in a previous life as a clinician at Women's College Hospital, I (Rice) worked with people's stories of vulnerability, hurt, and distress and used narrative and arts-based methods to support them in recognizing and rewriting those stories. I (Mündel) did my $\mathrm{PhD}$ work in literature and performance studies where I looked at storytelling and social change in Canada through a range of art forms-from novels and plays, through to performance art pieces, and community-based theater performances embedded in broader academic research projects. My (Rice's) PhD research (2014) examined the entanglement of a rich sampling of women's body stories with the larger cultural narratives told about their bodies. So, while in our early and continuing work as both humanities and social science scholars, we have examined, used, framed, and upheld storytelling and storywork as integral to our research practices, stories remain slippery to us as an analytic category. Maybe we have Thomas King to blame for this; he is the one who tells us that "The Truth about stories is that that's all we are" (King 2003:2). If that is the case, then where do we start?

Stories not only carry ideologies and discourses, they also author us and give us the means to author ourselves. We live the stories that get planted in us and we also live the stories we plant in ourselves. This cross-fertilization-of stories seeded by others and stories germinated by us-is what allows us to cultivate distinct subjectivities and shared identities; to create and express difference even as we create and express community and culture. This brings us to an important reason we have invested in storytelling: stories make us vulnerable to ourselves and others, make us ask questions about who we are and who we should be, make us take risks, go to uncharted places, and rethink ourselves in relation to others and the world.

I (Rice) would like to tell a story about the power of self-exploration and selfreflexivity in collaborative storytelling. I got the idea for Re•Vision in 2007 after making 
my first story in a digital storytelling workshop for women living with disabilities that ran as a part of a grant for which I was the lead researcher. At the time, I was working on a theoretical paper about self-reflexivity in embodiment research and knew that if I was asking women in the room to go to unmapped places I had to go to my own. The story I crafted, The Elephant in the Room, was one that could only have been created in a community of women who lived with disability, whose presence allowed me to disclose my bodily difference, to "come out" so to speak, and to story, authentically, who I was in relation to that research. (To view go to www.projectrevision.ca/story-making and type in the password "disrupting.")

How might the embodied subjectivity narrated in The Elephant in the Room be thought of as processual? In the video, I tell the story of growing up as a "fat girl" and of moving in the adult world as a white, middle class, normatively appearing woman-one whose body history and traumas are not written, or readable, on my skin. While my video can be read as a prototypical western transformation narrative where an improved self emerges from an amended body, one might also read its story of bodily self metamorphoses as radically destabilizing the normatively embodied subject. This is because the embodied self that I story violates the culturally preferred way of inhabiting one's body (as a bounded entity and container for the self) and because it unsettles the dominant narrative that a slim identity is more authentic, healthier, or worthier than a fat one. Although I see my story and all the stories created through Re•Vision as authentic in the sense of loyal and provisionally "true" representations, I no longer am the person I was when I made it. This highlights for both of us the multilayered meanings of the word "revision." While one can take Rich's interpretation of revision to mean uncovering an authentic truth hidden behind false assumption - a version that equates vision with truth-it is also possible to glean another meaning: rather than fixing or correcting past falsehoods to uncover a hidden truth, revision can be understood as a continuous process of revisiting, rethinking, and reworking — of understanding the self as a continuous process of changing, of becoming.

Winter

In Winter, another story that illustrates how the self might be thought as processual and story-making as a process of self-revision, Inuit sound and video artist 
Geronimo Inituq uses language to tell hybrid identities: singing and speaking himself in Inuktitut, French, English. (To view go to www.projectrevision.ca/story-making and type in the password "disrupting.") In his intimate encounter with Winter, a homeless Indigenous man living on the streets of Toronto, we learn that Winter has been relocated to 38 foster homes, and that his frequent cycling and recycling through the foster care system has resulted in the severing of his connections to family, community, and culture. Though both Inutiq and Winter carry very different histories and legacies of colonialization and claim different identities and belongings-Inutiq as Inuit, French, and English, and Winter as First Nations-they also recognize through these differences their shared experiences of colonial violence and resistance, evoking a pan-Indigenous affinity wrought by these legacies. In this chance encounter, Inutiq gives us a glimpse of postcontact history from the vantage points of those bonded through and against the multilayered brutalities of settler colonialism. Underscoring the processual nature of subjectivity and becoming, Inutiq's own gaze and presence remains concealed in the story. While his voice is clear and strong in his telling of his narrative, the only moment where we see a visual representation of Inutiq is when we see a shadow of him holding a camera in the final shot of the video. In this way Inutiq's identity remains elusive, defying being tied down in some kind of authoritative narrative of who he is or is expected to be as an urban Inuit person.

\section{Revising Intersubjectivities and Relationalities}

For us, something that is critical to our story-making process is that people tell their own stories within a collaborative framework, and one in which the people being centered may have different histories and relationships to institutions and systems. This approach centers the necessity of listening. In this, we draw on Indigenous storytelling traditions that ask listeners to pay close attention. As Archibald (1997) writes: "the oral tradition implicates the 'listener' into becoming an active participant in the experience of the story. An inter-relationship between the story/storyteller/listener is a critical principle of storytelling" (p. 40). There is an interesting rub between the centering and telling of marginalized voices and the careful framing, editing, and positioning that each storyteller navigates to tell their story. Voice in the workshop is at once singular, particular, and also embedded and interconnected with a web of both absent and 
present listeners. During the workshops, we have observed a critical interplay between storytellers, facilitators, and researchers-the storytellers' own stories are not discrete, individual, nonporous. Rather, the process of story development becomes a collective process based on shared context and time frame, where stories begin to bleed and breathe into each other. Through these processes, storytellers individually and collectively consider imagined audiences of their stories as well as reflect on hegemonic narratives and ethical questions about the experiences they seek to (re)tell. As mine (Rice's) and Laura Eggertson's stories discussed above show the process of telling and listening creates space for shared creativity and mutual accountability. While many discussions of storytelling for social change focus on the importance of individuals telling their stories, of talking back to dominant narratives, what we find equally important is the work that this process does in recentering the necessity of listening, and through attending closely, of revising our relationalities with each other.

Importantly, our collaborative framework also extends to the research apparatus itself. Rather than undertaking research about or for justice seeking groups, we design and implement research processes by and with communities. For example, Re•Vision's involvement in Indigenous research emerged through our partnership with Dr. Susan Dion (Pottawatomi, Lenape), a well-known scholar in Indigenous education, and through her, a network of Métis, First Nations, and Inuit artists and academics with whom we have cultivated relationships. By bringing together the stories of Indigenous and nonIndigenous people, Re•Vision's work on Indigenous-settler relations represents a polyvocal (multivoiced) response to colonization processes in settler societies such as Canada, New Zealand, Australia, and South Africa. As the stories featured here make plain, it is a profound injury and ongoing source of trauma that these legacies continue to shape Indigenous people's experiences in encounters with non-Indigenous people, in mainstream institutions, and in relations with the Canadian state. The stories made in the Indigenous workshops further reveal the urgent, substantive work that we as nonIndigenous settler researchers must undertake to revise our ways of knowing ourselves, Indigenous people, and the world. 
S/Kin

The final two stories we discuss emphasize intersubjectivity and relationality of storytelling, and feature stories made in Indigenous-settler workshops. In S/Kin, a video made by Allison Crawford, a white-settler psychiatrist and storyteller who participated in the same workshop as Komanjapik (next), emphasizes the interconnectivity of storytelling in intimate ways through telling of a story of decolonial love-her love for her Inuit children. (To view go to www.projectrevision.ca/story-making and type in the password "disrupting.") Layering the sounds and images of the drum-the heartbeat of the nation-with anatomical renderings of the heart, she untangles and entangles the complexities of loving where skin both binds and severs kin. Here, we might read the slash that both connects and splits S/kin as a marker of the western colonial logics that impose certain binaries on bodies and relations-Inuit/qallunaat, relative/stranger, self/other, mother/nonmother-creating meta-physical cuts that the physical intimacies described in the video seek to mend. Crawford's revising of the meaning of motherhood in ways that resist biological reductionism while still insisting on the intracorporeal intimacies of mother and infant opens possibilities for new relationalities across these bodies and histories. These new relationalities carry the potential to remake the meanings of motherhood, and through (re)presenting mother-child corporeal closeness in difference-affirming ways to remake the very meanings of kin.

\section{Qalunagsiuti}

In Qalunagsiuti, Inuit sculptor and metalwork artist Ruben Komanjapik (re)turns the colonial gaze by staging a reverse ethnography that makes a spectacle of white ways, using improvisation and humor to draw attention to the hegemony of the English language and of the written word. (To view go to www.projectrevision.ca/story-making and type in the password "disrupting.") Here, Komanjapik subverts the multimedia storytelling genre's typical emphasis on storytelling as a solitary or scripted enterprise through joining with other Inuit storytellers to improvise a collective (re)telling and (re)turning of the colonial gaze. From the opening shot, white features-eyes, torso, ears-become objects of the Inuit gaze. As the film's narrative unfolds, a panel of ostensibly Inuit researchers invite a white man to perform a comically simplistic skill for them: reciting his $A B C s$. The mock formality and solemnity with which these experts 
celebrate the white man's kindergarten-coded accomplishment call to mind a history of white-Inuit relations in which in Inuit languages, cultures, knowledges, and ways of life were dissected and subjected to the sterile gaze of western science, perhaps revealing how its ways of seeing have limited and distorted what could (and still can) be seen.

What emerged as significant for us, as white-settler researchers involved in facilitating an Inuit-qallunaat (non-Inuit) storytelling project with a mixed team of white and Indigenous researchers (with only one facilitator identifying as Inuit) is the metachallenge to our methodology issued by Komanjapik's video. Rather than following facilitator instructions to craft an individualized story centering on his personal experience-his self-exploration of Inuit identity and futurity-Komanjapik organized other Inuit storytellers in the workshop to tell a collective story. Using humor (tinged with shaming) as an affecting pedagogical device, this storytelling collective took the whiteness of our research methodology, along with its privileging of white subjectivity and its deeply individualist investment in self-examination, to task. The playful, pedagogic result has taught us to turn the gaze on our white-settler subjectivities and further, on the ways that whiteness shapes our research methodologies, even when we declare these to be decolonized. In Komanjapik's telling, we learned how the interrelationship between the story/storyteller/listener, which Archibald $(1997,2008)$ understands to be a critical principle of storytelling, required us as listener-researchers to think about our own historical, cultural, and current contexts in relation to the story being told. His telling galvanized us to rethink our focus on individuals telling their stories, expanding and stretching our methodology to facilitate more collective and improvisational approaches to story-making.

\section{CONCLUSION: PEDAGOGICAL AND EMANCIPATORY POSSIBILITIES OF MULTIMEDIA STORY-MAKING}

So, what are the pedagogical and emancipatory possibilities of this work? Since beginning Re•Vision, we have become interested how art and story-making might teach and provoke change. Questions about the pedagogical and emancipatory potential of activist arts and story-based methodologies are especially urgent given the shrinking space for agentic grassroots action in neoliberal contexts such as our own. In many 
small and sometimes big ways, we witness, through our research collaborations, the work of story and art in the world. These changes, small and large, occur through the work of self-revising that is integral to our group-based narrative methods, through the remaking of methodology that occurs with every research project we undertake, and through the constitution and reshaping of community as we collectively reconfigure our relationalities across institutional structures and communities. In Jackson's video, for example, the blurring of boundaries between self and other emerges as ripe with both possibility and peril; Eggertson also speaks to the wonders and dangers of storytelling by raising ethical questions about the complexities of telling stories that seek to acknowledge affinities in ways that still respect histories of difference. For me (Rice), storytelling presents a moment of sociopolitical possibility as I narrate experiences that pry open space for the creation of new communities across bodies of difference. While Inutiq evades the simple categories into which others might slot him, he also evokes a pan-Indigeneity wrought by colonial histories and legacies. Finally, Crawford and Komanjapik revise relationalities in highly intimate and overtly political ways, making new meanings of kin, community, and nation, and in so doing, of the research enterprise itself. In these examples, social change happens through the self-revising and relational reconfiguring that occur within the workshop space, and through these processes, in the scaffolding intersectional and intersectorial alliances (across institutions and communities) for intervening in inequities. In addition, change making continues post workshops, through where and how the stories travel and how researchers use them to influence policy and practice. We suggest that Re・Vision stories (and the collaborative framework for producing them) may function as "becoming" pedagogies that open nondidactic possibilities for living in/with/across difference. While nondidactic, the stories made and the story-making process itself are still instructive and productive insofar as they open us to new possibilities for relating and living. By doing this work, we aim to make space for methodologies that expand opportunities for creativity and relationality, for facilitating the becoming of subjectivities and communities. 


\section{References}

Adichie, C. 2009. "The Danger of a Single Story." TED Global Talks. Retrieved December 17, 2017 (http://www.ted.com/talks/chimamanda adichie the danger of a single story.ht $\underline{\mathrm{ml}})$.

Alexandra, D. 2008. "Digital Storytelling as Transformative Practice: Critical Analysis and Creative Expression in the Representation of Migration in Ireland." Journal of Media Practice 9 (4): 100- 12.

Archibald, J. 1997. "Coyote Learns to Make a Storybasket: The Place of First Nations Stories in Education." PhD Dissertation Faculty of Education, Simon Fraser University.

Archibald, J. 2008. Indigenous Storywork: Educating the Heart, Mind, Body, and Spirit. Vancouver, BC: University of British Columbia Press.

Bal, M. 1997. Narratology: Introduction to the Theory of Narrative. Translated by Christine Boheemen. 2nd ed. Toronto: UT Press.

Behar, R. 1996. The Vulnerable Observer: Anthropology that Breaks Your Heart. Boston, MA: Beacon Press.

Beltrán, R. and S. Begun. 2014. "It is Medicine": Narratives of Healing from the Aotearoa Digital Storytelling as Indigenous Media Project (ADSIMP)." Psychology and Developing Societies 26 (2): 155- 79.

Benmayor, R. 2008. "Digital Storytelling as a Signature Pedagogy for the New Humanities." Arts and Humanities in Higher Education 7 (2): 188- 204.

Boje, D.M. 2011. Storytelling and the Future of Organizations: An Antenarrative Handbook. New York, NY: Taylor and Francis.

Braidotti, R. 2013. The Posthuman. Cambridge, UK: Polity Press.

Brushwood Rose, C. 2009. "The (Im)possibilities of Self-Representation: Exploring the Limits of Storytelling in the Digital Stories of Women and Girls." Changing English 16 (2): $211-20$.

Clandinin, D.J. and F.M. Connelly. 2000. Narrative Inquiry: Experience and Story in Qualitative Research. San Francisco, CA: Jossey-Bass. 
Cole, A.L. and J.G. Knowles. 2001. Lives in Context: The Art of Life History Research. Toronto: Rowman \& Littlefield/Altamira Press.

Conquergood, D. 2002. "Performance Studies." TDR/The Drama Review 46 (2): 14556.

Cronin, J.K. 2011. "Toward a Conclusion: A Focus on the Visual Culture of Activism." Pp. 243- 49 in Imagining Resistance: Visual Culture and Activism in Canada, edited by J.K. Cronin and K. Robertson.Waterloo, ON: Wilfrid Laurier University Press.

Dufour, K. 2002. "Art as Activism, Activism as Art." Review of Education, Pedagogy \& Cultural Studies 24 (1-2): 157- 67.

Felshin, N. 1995. "Introduction." Pp. 9- 29 in But is It Art? The Spirit of Art as Activism, edited by N. Felshin. Seattle, WA: Bay Press.

Ferrari, M., C. Rice and K. McKenzie. 2015. "Retracing African, Caribbean, and European (ACE) Pathways Project: Digital Storytelling." Psychiatric Services 66 (5): 556- 59.

Finley, S. 2008. "Arts-Informed Research." Pp. 71- 82 in Handbook of the Arts in Qualitative Research: Perspectives, Methodologies, Examples, and Issues, edited by G.J. Knowles and A. Cole.Thousand Oaks, CA: Sage.

Finley, S., C. Vonk and M.L. Finley. 2014. "At Home at School: Critical Arts-Based Research as Public Pedagogy." Cultural Studies <-> Critical Methodologies 14 (6): 619-25.

Fludernik, M. 2005. "Histories of Narrative Theory (II): From Structuralism to the Present." Pp. 36- 59 in A Companion to Narrative Theory, edited by J. Phelan and P.J. Rabinowitz. Hoboken, NJ: John Wiley \& Sons.

Frank, A.W. 2010. Letting Stories Breathe: A Socio-Narratology. Chicago, IL: University of Chicago Press.

Georgakopoulou, A. 2015. "Small Stories Research: Methods-Analysis-Outreach." Pp. 255- 72 in Handbook of Narrative Analysis, edited by A. Fina and A. Georgakopoulou. Malden, MA: John Wiley and Sons. 
Gubrium, A., E. Krause and K. Jernigan. 2014. "Strategic Authenticity and Voice: New Ways of Seeing and Being Seen as Young Mothers through Digital Storytelling." Sexuality Research and Social Policy 11: 337- 47.

Kim, J.H. 2015. Understanding Narrative Inquiry: The Crafting and Analysis of Stories as Research. Thousand Oaks, CA: Sage Publications.

King, T. 2003. The Truth about Stories: A Native Narrative. Toronto, ON: Anansi Press. Knowles, J.G. and A.L. Cole. 2008. "Arts-Based Research." Pp. 32- 36 in The Sage Encyclopedia of Qualitative Research Methods, edited by L.M. Given. Los Angeles, CA: Sage.

Lambert, J. 2013. Digital Storytelling: Capturing Lives, Creating Community. New York: Routledge.

Leavy, P. 2009. Method Meets Art: Arts-Based Research Practice. New York: Guildford. Lind, E., C. Kotow, C. Rice, J. Rinaldi, A. LaMarre, M. Friedman and T. Tidgwell. 2017. "Re-Conceptualizing Temporality in and through Multi-Media Storytelling: Making Time with through Thick and Thin." Fat Studies 7: 1-12.

Ortega, A. 2014. "Looking into the Eye of the Process: Intercultural Art Activism Trans*/lations and Intersex/tions in the Global South." Agenda 28 (4): 86- 93.

Papalia, C. 2018. "An Accessibility Manifesto for the Arts." Canadian Art Winter: 1-2. Retrieved December 17, 2017 (https://canadianart.ca/features/access-revived/).

Pink, S. 2015. Doing Sensory Ethnography. 2d ed. Thousand Oaks, CA: Sage Publications.

Platt, S. 1997. "Art and Activism: A Brief History." Art Papers 21 (3): 18- 20.

Raphael, R. 2013. "Art and Activism: A Conversation with Liz Crow." Journal of Visual Art Practice 12 (3): 329- 44.

Reissman, C.K. 2008. Narrative Methods for the Social Sciences. Thousand Oaks, CA: Sage Publications.

Rice, C. 2014. Becoming Women: The Embodied Self in Image Culture. Toronto, ON: UT Press.

Rice, C., E. Chandler and N. Changfoot. 2016. "Imagining Otherwise: The Ephemeral Spaces of Envisioning New Meanings." Pp. 54- 75 in Mobilizing Metaphor: Art, 
Culture and Disability Activism in Canada, edited by C. Kelly and M. Orsini. Vancouver, BC: UBC Press.

Rice, C., E. Chandler, E. Harrison, M. Ferrari and K. Liddiard. 2015. "Project Re•Vision: Disability at the Edges of Representation." Disability \& Society 30 (4): 513- 27. Rice, C., E. Chandler, K. Liddiard, J. Rinaldi and E. Harrison. 2016. "The Pedagogical Possibilities for Unruly Bodies." Gender \& Education. Retrieved December 17, 2017 (https://doi-org.subzero.lib.uoguelph.ca/10.1080/09540253.2016.1247947).

Rice, C., E. Chandler, J. Rinaldi, K. Liddiard, N. Changfoot, R. Mykitiuk and I. Mündel. 2017. "Imagining Disability Futurities." Hypatia 32 (2): 213- 29.

Rice, C., S. Dion, I. Mündel and H. Fowlie. 2018a. "Re/Turning the Gaze: Unsettling Settler Logics through First-Person Narrative Filmmaking." Unpublished manuscript.

Rice, C., A. LaMarre, N. Changfoot and P. Douglas. 2018b. "Making Spaces: Multimedia Storytelling as Reflexive, Creative Praxis." Qualitative Research in Psychology. Retrieved March 27, 2018 (https://doiorg.subzero.lib.uoguelph.ca/10.1080/14780887.2018.1442694).

Rice, C. and I. Mündel. Forthcoming. "Multimedia Storytelling Methodology: Notes on Access and Inclusion in Neoliberal Times." Canadian Journal of Disability Studies.

Rice, C., K. Pendleton Jiménez, E. Harrison, M. Robinson, J. Rinaldi, A. LaMarre and J. Andrew. Forthcoming. "Bodies at the Intersection: Reconfiguring Intersectionality through Queer Women's Creative Accounts of Their Complex Embodiments." Signs: A Journal of Women in Culture and Society.

Rich, A. 1972. "When We Dead Awaken: Writing as Re-Vision." College English 34 (1): $18-30$.

Rinaldi, J., C. Rice, A. LaMarre, K. Pendleton Jiménez, E. Harrison, M. Friedman, D. McPhail, M. Robinson and T. Tidgwell. 2016. “Through Thick and Thin': Storying Queer Women's Experiences of Taking Up and Resisting Idealized Body Images and Expected Body Management Practices." Psychology of Sexualities Review (PoSR) 7( 2): 63- 77. 
Rose, G. 2016. Visual Methodologies: An Introduction to Researching with Visual Materials. 4th ed. Thousand Oaks, CA: Sage Publications.

Sontag, S. 2003. Regarding the Pain of Others. New York, NY: Farrar, Straus, and Giroux.

Vivienne, S. 2011. "Trans Digital Storytelling: Everyday Activism, Mutable Identity and the Problem of Visibility." Gay \& Lesbian Issues and Psychology Review 7 (1): 43- 54.

White, M. 2007. Maps of Narrative Practice. New York: WW Norton \& Company.

Willox, A., S. Harper and V. Edge. 2012. "Storytelling in a Digital Age: Digital Storytelling as an Emerging Narrative Method for Preserving and Promoting Indigenous Oral Wisdom." Qualitative Research 13 (2): 127- 47. 